\title{
EFFECT OF LIGHT AND SOIL NUTRIENT ON SEEDLING MORPHOLOGY OF Syzygium SPECIES OF A LOWLAND RAIN FOREST IN SRI LANKA
}

\author{
H K Gamage', BM P Singhakumara', P M S Ashton² \\ University of Sri Jayewardenepura, Nugegoda.

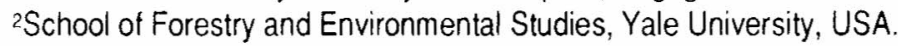

Knowledge of how light and soil nutrient availability affect secdling morphology in relation to seedling growth is critical for understanding the regeneration establishment of seedlings beneath rain forest eanopies. This study measured changes in seedling morphology of four related tree species in the family Myrtaceae in relation to differing combinations of light and soil nutrients. Species selected were canopy and sub canopy trees of rain forest in southwest Sri Lanka.

Shelters were constructed in the full open that created light treatments representing a range of photosynthetic Photon Flux Densities (PFD) and red : far red ratios found in the rain forest. Within each shefter seedlings were fertilised with phosphorous, potassium and magnesium nutrients. Newly germinated seedlings of each of four species (S. firmum, $S$. makul, S. operculaum, S. rubicundum) were grown lor one and half years after which they were dug up and measured for. shoot length, root length, root collar diameter, Icaf number. leaf area. and dry masses of roots. stems and leaves.

Shoot length and leal area attained maxima in shelters simulating large forest openings $\left(40\left(1 \mathrm{~m}^{2}\right)\right.$. Root length, root collar diameter and dry masses gain were highest in full sun treatment. Compared with nutrient treatments phosphorus promoted greatest morphological measurements for all species. The results suggest that these species exhibit greater morphological responsiveness to increase in irradiance and 10 addition of phosphorous fertiliser.

Proce'edings of the Fourth Annual Forestry and Environment Symposium 1998 of the Department of Forestry and Environmental Science, University of Sri Jayewardenepura, Sri Lanka 